\title{
Fetal cardiac circulation in isolated aortic atresia assessed with ultrasound
}

\section{izole aortik atrezide fetal kardiyak dolaşımın ultrason eşliğinde değerlendirilmesi}

\author{
Aslı Tanrıvermiş Sayit ${ }^{1}$, Ali İpek ${ }^{1}$, Aydın Kurt ${ }^{2}$, Bayan G. Aghdasi³ ${ }^{3}$ Halil Arslan ${ }^{1}$, Mehmet Gümüşs $^{1}$ \\ 'Department of Radiology, Ankara Ataturk Education and Research Hospital, Ankara, Turkey \\ ${ }^{2}$ Department of Radiology, Ankara Etlik Ihtisas Education and Research Hospital, Ankara, Turkey \\ ${ }^{3}$ Medical Student, David Geffen School of Medicine at University of California, Los Angeles, USA
}

\section{Abstract}

Congenital heart diseases are common, with an incidence of more than 8 in 1000 live births. Aortic atresia is a rare diagnosis and its prognosis is very poor. In this article, we present a case of isolated aortic atresia, a very rare cardiovascular anomaly, and its fetal ultrasound findings which include blood flow at foramen ovale from left to right, right deviation of the interventricular septum, dysfunction of the mitral valve and cardiomegaly. Aortic stenosis should be considered in the differential diagnosis of aortic atresia. However, in the case of severe aortic stenosis and/or accompanying ventricular septal defect, differential diagnosis may not be done.

(J Turkish-German Gynecol Assoc 2012; 13: 281-3)

Key words: Aortic atresia, cardiovascular anomaly, congenital heart disease, color Doppler ultrasound, fetus

Received: 04 April 2012

Accepted: 12 May 2012
Özet

Konjenital kalp hastalıkları çok sık görülmekte olup insidansı 1000 canlı doğumda 8' den fazladır. Aortik atrezi nadir görülmekte olup prognozu kötüdür. Biz bu olgu sunumunda, ultrasonografi bulguları arasında foramen ovaleden soldan sağa şant, interventriküler septumda sağa deviasyon, mitral kapakta disfonksiyon ve kardiyomegalinin izlendiği nadir görülen bir kardiyovasküler anomali olan aort atrezisini tartışmayı amaçladık. Aort atrezisinin ayıııı tanısında mutlaka aort stenozu göz önünde bulundurulmalıdır. Ancak şiddetli aort stenozuna eşlik eden VSD varlığında ayırıcı tanı yapılamayabilir.

(J Turkish-German Gynecol Assoc 2012; 13: 281-3)

Anahtar kelimeler: Aort atrezisi, fetüs, kardiyovasküler anomali, konjenital kalp hastalığı, renkli Doppler ultrason

Geliş Tarihi: 04 Nisan 2012

Kabul Tarihi: 12 Mayıs 2012

\section{Introduction}

Congenital heart diseases (CHD) are common, and are seen with an incidence greater than 8 in 1000 live births. These anomalies can cause severe morbidity and mortality in the fetus and neonate (1). Among CHD, atrioventricular septal defect, hypoplastic left heart syndrome, coarctation of the aorta, tricuspid dysplasia/Ebstein's anomaly and ventricular septal defect are the most common (2). In this article, we present a case of isolated aortic atresia, which is a very rare cardiovascular anomaly, and the fetal color Doppler ultrasound (USG) findings and assessment of secondary hemodynamic changes.

\section{Case Report}

At the fetal USG of a 24 year old pregnant woman (gravida 1, para 0) a 25 weeks and 4 days old male fetus was seen. According to her last menstrual cycle, the mother had been pregnant for 25 weeks. This was her first visit to our clinic. There was no family history of CHD. In the fetal USG, the position and axis of the heart were normal, and upon visualization of three vessels, the localizations of the pulmonary artery (PA) and superior vena cava were also normal. There was no vascular outflow tract at the left ventricle. The ascending aorta had a ligamentous appearance and its diameter was measured as 1 $\mathrm{mm}$ (Figure 1a and b). Blood flow at the foramen ovale from left to right, right deviation of the interventricular septum, dysfunction of the mitral valve and cardiomegaly were detected on the color Doppler USG (Figure 2 and 3). The diameter of the PA was measured to be wider than normal $(7.2 \mathrm{~mm})$, and the ductus arteriosus (DA) was dilated. Because of the obstruction at the left ventricular outflow tract and the dysfunction of the mitral valve, blood flowed back to the left atrium from the left ventricle and went to the right atrium by passing through the foramen ovale. Most of the blood passing to the right ventricle was going to the systemic circulation by the DA. Blood coming to the left atrium by the pulmonary veins was going to the right atrium by the foramen ovale too. No atrioventricular

Address for Correspondence: Aslı Tanrivermiş, Sayit, Department of Radiology, Ankara Ataturk Education and Research Hospital, 06800 Ankara, Turkey Phone: +00905324949082 e.mail: draslitanrivermissayit@gmail.com 

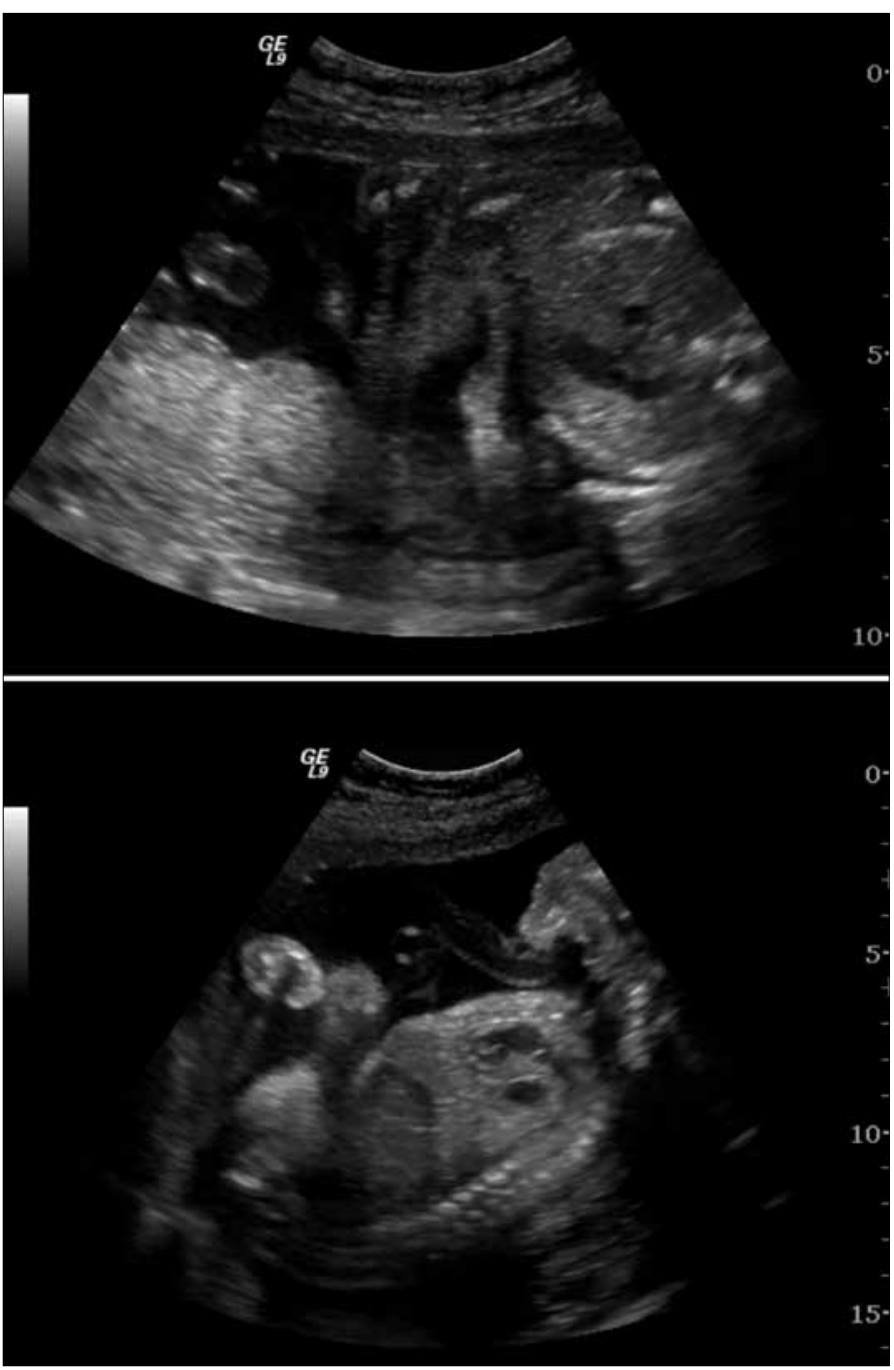

Figure 1. a) Axial three-vessel view; ascending aorta is not seen b) Sagittal sonography; Pulmonary artery behind the aortic root was not observed

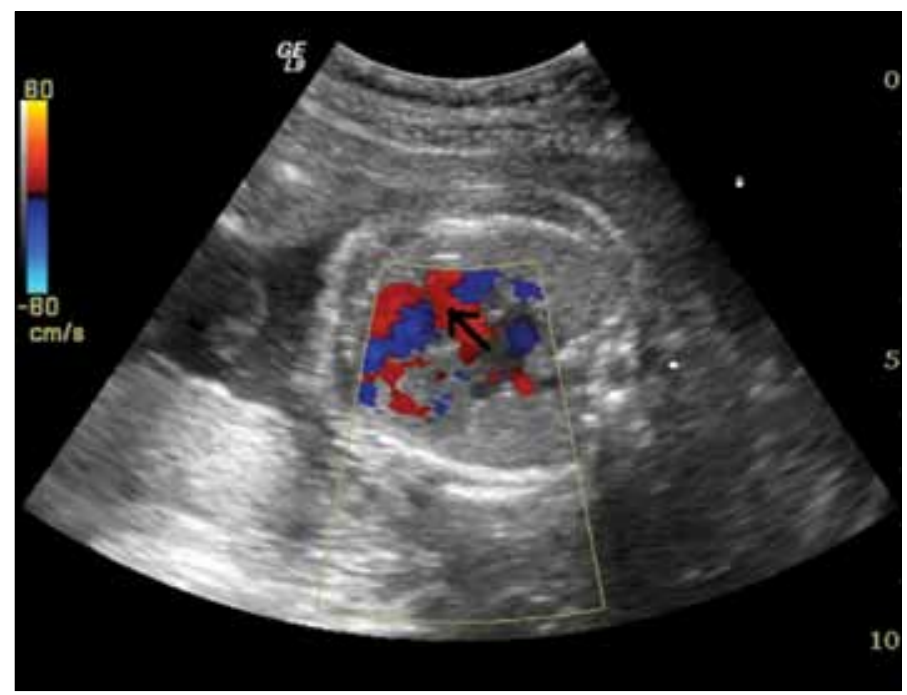

Figure 2. Blood flow from left to right through the foramen ovale is seen in color Doppler ultrasound

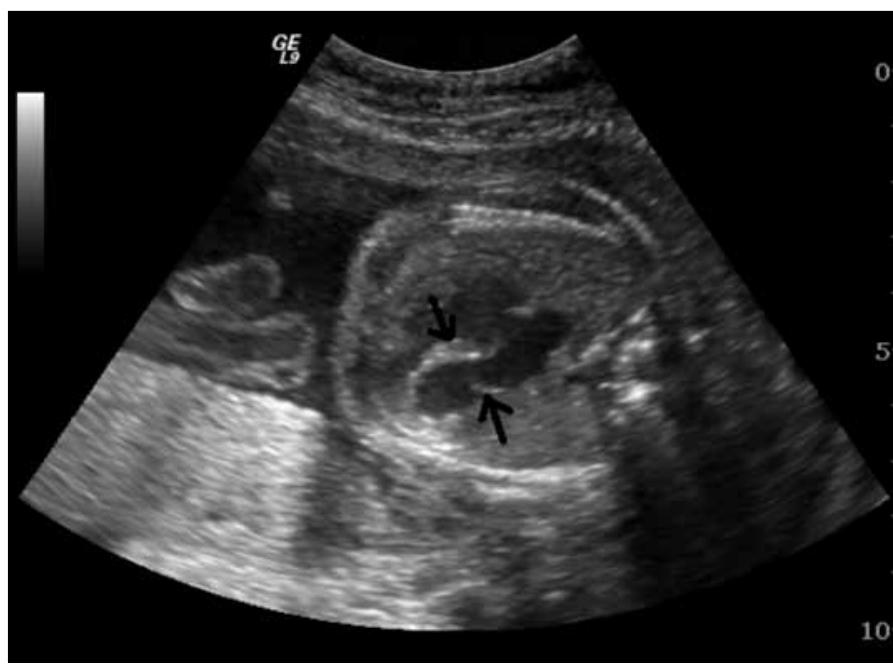

Figure 3. Mild right deviation of the interventricular septum and relaxation of the mitral valve are seen in axial sonography

septal defect or other organ anomalies were detected. After a pediatric cardiology consultation, the patient was offered to be delivered, but she did not accept the procedure. The fetus was born at term, but died just 6 hours after. The family did not agree to a postmortem autopsy.

\section{Discussion}

Fetal cardiac USG is a very simple and sensitive diagnostic procedure for the diagnosis of CHD. A four-chamber view of the heart has been proposed as a routine portion of the fetal USG to be obtained at visits from 18 weeks to term. The position of the heart, approximately equal size of the ventricles, the foramen ovale opening to the left atrial cavity, and the positioning of both atrioventricular valves are important items to look for. However, if only the four-chamber assessment is made, ventricular outflow tracts or the great artery anomalies may be missed. The relationship between the aorta and the left ventricle is assessed by a long axis view of the ventricle (1). The three vessels are assessed by longitudinal scans to the level of fetus's uppermost mediastenium transverse scan. The trunk of the PA, ascending aorta and superior vena cava are all arranged in a straight line in this view. The imaging of these three-vessels gives important information about potential abnormal diameters and positioning of the vessels, and pathological relationships between the ascending aorta and trunk of the PA (3). Absence of flow out of the left ventricle through the aortic valve is suggestive of aortic atresia. Reverse flow from the DA into the aortic arch and a hypoplastic ascending aorta is an indirect sign of severe left ventricular outflow tract obstruction.

It is diagnostic of aortic atresia when the internal diameter of the ascending aorta is less than $5 \mathrm{~mm}$. It is seen with a hypoplastic mitral valve, and rarely with mitral atresia and a hypoplastic left ventricle or rudimentary left ventricle without a left atrioventricular connection. If the mitral valve is patent, the size of the ventricles may be different $(4,5)$. In our case, the diameter of the ascending aorta was $1 \mathrm{~mm}$ and it was ligamentous in appearance. Because of the mitral valve insufficiency, there 
was a mild dilatation of the left ventricle and cardiomegaly. Tometzki et al. presented a fetus with a normal size ventricle with aortic atresia, pulmonary stenosis, VSD and truncus arteriosus (6). In our case, the output of the PA from the ventricle was normal, whereas the diameter of the PA was $7.2 \mathrm{~mm}$. The aorta was in the normal position and of a normal size at the level of the DA. There was no additional cardiac pathology such as atrial or ventricular septal defects.

Altough the myocyte number is increased initially in fetuses with aortic atresia and a patent mitral valve, later the proliferative phase stops and a hypoplastic left ventricle may develop (7). Hypoplastic left heart syndrome is a wide-spectrumed malformation associated with a small left ventricle and aortic atresia and an atresic or hypoplastic mitral valve. Andrew et al. reported a monochorionic twin pregnancy in which both of the fetuses had hypoplastic left heart syndrome. They detected a small left ventricular cavity and hypoplastic aortic arch in the first fetus and no ventricular cavity and a bright ecogenity in its place in the second fetus. The gestation was terminated at 17 weeks, hypoplastic left heart syndrome was verified and mitral and aortic atresia were detected at autopsy $(7,8)$. In this case, because mitral valve failure developed with aortic atresia, mild dilatation of the left ventricle, diffuse cardiomegaly, and a mild left deviation of the interventricular septum were seen. Blood flow from left to right through the foramen ovale due to increased pressure in the left atrium was visualized with color Doppler USG. In this case, because of the fetus's own special circulation, there was cardiomegaly, and hypoplastic left heart syndrome did not seem to apply. Gembruch et al. (4) reported a 33 week old fetus with aortic atresia and mitral valve insufficiency, left ventricular hypertrophy and premature closing of the foramen ovale. Because of this, volume overload in the right ventricle and congestive cardiac failure developed.

Early closing of the foramen ovale causes hydrops fetalis. Also, fetuses with severe aortic obstruction and mitral valve insufficiency with a predominant shunt from left to right have overloading of the right heart and hydrops. Fetuses with aortic atresia but without VSD require decompression of the left atrium provided by an interatrial shunt from left to right. In our case, because of the absence of a VSD, flow from the left to right atrium was occuring through the foramen ovale. Because of a predominantly left to right shunt by the foramen ovale, mild growth and overloading of the right heart was detected, but non-immune hydrops was not seen.

Reverse flow into the aortic arch through the ductus arteriosus and a hypoplastic ascending aorta together point to severe left ventricular outflow tract obstruction. The absence of flow out of the left ventricle through the aortic valve should draw attention to aortic atresia. Absence of forward flow at color Doppler USG, reverse flow in the hypoplastic aortic tract and mitral regurgitation are important diagnostic criteria for aortic atresia. Expansion of the left atrium and ventricle, mitral valve insufficiency and hypofunction of the left ventricular myocardium are seen in complete left ventricle outflow tract obtruction. In such cases, there is a high risk of hydrops fetalis.

Aortic atresia and aortic stenosis have similar findings in twodimensional imaging. However, unlike aortic atresia, aortic stenosis causes acceleration of prestenotic blood flow in the left ventricular outflow tract, and poststenotically an antegrade jet with very high velocities and turbulence in the ascending aorta is seen in color Doppler USG. If the stenosis is very severe and/or there is a VSD, in the situation of a patent aortic valve antegrade stenotic jet flow will not be seen and the differential diagnosis of aortic atresia can not be made. If a critical aortic stenosis exists, the degree of ascending aorta hypoplasia and the anatomic situation of the left ventricle wall will indicate inoperability $(4,9)$.

The ductus arteriosus closes 48 hours after birth. The systemic circulation obliterates due to closing of the ductus arteriosus and that results in hypoxia. As a result the neonate dies (10). In our case we thought the systemic circulation was obliterated due to the closing of the ductus arteriosus and that this caused cyanosis and death. Because the family did not consent to an autopsy, histopathological diagnosis could not be used to confirm the cause of death.

\section{Conclusion}

Cardiovascular anomalies have an important place in obstetric USG findings. In a routine fetal cardiac USG of the four chambers of the heart, the great vessels and ventricular outflow tracts must be seen.

\section{Conflict of interest}

No conflict of interest was declared by the authors.

\section{References}

1. McGhan JP. Sonography of the fetal heart: Findings on the fourchamber view. Am J Roentgenol 1991; 156: 547-53.

2. Allan LD, Sharland GK, Milburn A, Lockhart SM, Groves AM, Anderson $\mathrm{RH}$, et al. Prospective diagnosis of 1,006 consecutive cases of congenital heart disease in the fetus. J Am Coll Cardiol 1994; 23: 1452-8. [CrossRef]

3. Yoo SJ, Lee YH, Cho KS. Abnormal three-vessel view on sonography: a clue to the diagnosis of congenital heart disease in the fetus. Am J Roentgenol 1999; 172: 825-30.

4. Gembruch U, Chatterjee M, Bald R, Eldering G, Gocke H, Urban AE, et al. Prenatal diagnosis of aortic atresia by color Doppler flow mapping. Prenat Diagn 1990; 10: 211-7. [CrossRef]

5. Bardo DM, Frankel DG, Applegate KE, Murphy DJ, Saneto RP. Hypoplastic left heart syndrome. Radiographics 2001; 21: 705-17.

6. Tometzki AJ, Suda K, Kohl T, Kovalchin JP, Silverman NH. Accuracy of prenatal echocardiographic diagnosis and prognosis of fetuses with conotruncal anomalies. J Am Coll Cardiol 1999; 33: 1696-701. [CrossRef]

7. Andrews RE, Cook AC, Yates RW. Concordance for hypoplastic left heart syndrome in a monochorionic twin pregnancy. Heart 2003; 89: 13. [CrossRef]

8. Barboza JM, Dajani NK, Glenn LG, Angtuaco TL. Prenatal diagnosis of congenital cardiac anomalies: a practical approach using two basic views. Radiographics 2002; 22: 1125-38.

9. Benacerraf BR. Sonographic detection of fetal anomalies of the aortic and pulmonary arteries: value of four-chamber view vs direct images. Am J Roentgenol 1994; 163: 1483-9.

10. Mysorekar VV, Dandekar CP, Rao SG. Single ventricle with mitral and aortic atresia. Bahrain Med Bull 2004; 26: 1-6. 